\title{
Um olhar (enunciativo) para o conceito de língua no trabalho de sala de aula
}

Claudia Toldo*

Gabriela Schmitt Prym Martins ${ }^{* *}$

\section{Resumo}

Este artigo objetiva discutir o conceito de língua no Curso de linguística geral, de Ferdinand de Saussure (2012), e nos textos "A forma e o sentido na linguagem" e "Semiologia da língua”, de Émile Benveniste (1989). Esta escolha teórica se justifica pela necessidade de conceituar língua, buscando uma reflexão sobre seu ensino na escola de educação básica. A partir dessas leituras, percebemos que a relação entre os autores sobre o conceito de língua ocorre, principalmente, através da noção de signos organizados em um sistema. Neste artigo, ao refletirmos sobre a relação entre os autores, percebemos que uma aproximação teórica é possível se tomarmos a língua em uso, com os signos manifestados na coletividade, o que, inegavelmente, é relevante ao pensarmos o ensino de língua na escola de educação básica. Para tanto, realizamos uma pesquisa bibliográfica e exploratória, em que percebemos que uma noção enunciativa de língua é uma das possibilidades de trabalho efetivo com a língua materna na escola.

Palavras-chave: Conceito de língua. Ensino de língua materna. Linguística saussuriana. Linguística benvenistiana.
* Professora tempo integral de Língua Portuguesa e Linguística no Curso de Letras da Universidade de Passo Fundo (UPF/RS). Possui Graduação em Letras pela UPF/RS (1990), Especialização em Ensino de Língua Portuguesa pela PUC/MG (1992), Mestrado em Letras (Área de concentração: Teorias do texto e do Discurso) pela Universidade Federal do Rio Grande do Sul (1999), Doutorado em Linguística pela Pontifícia Universidade Católica do Rio Grande do Sul (2002) e Pós-doutorado em Linguística, na Universidade Federal do Rio Grande do Sul (2012), com bolsa Capes. Atualmente é supervisora de ensino da Rede de Educação Notre Dame. Na UPF, atua como professora de Língua Portuguesa e Linguística do Curso de Graduação em Letras e professora/orientadora do Programa de Pós-graduação (Mestrado e Doutorado) em Letras, da mesma Universidade. Realiza estudos na área da Linguística, com ênfase na Linguística da Enunciação, e Linguística do Texto, dedicando-se - principalmente ? ao estudo dos seguintes temas: enunciação (teorias de Émile Benveniste), ensino de língua materna, abordando questões referentes ao ensino da leitura, da produção textual e da sintaxe. Foi Coordenadora Institucional do Pibid/ UPF - Programa Institucional de Bolsa de Iniciação à Docência. Atualmente é Coordenadora do Programa de Pós-Graduação em Letras/PPGL. É pesquisadora e bolsista Produtividade em Pesquisa - PQ/CNPq. E-mail: claudiast@upf.br

** É doutoranda em Letras - Constituição e Interpretação do Texto e do Discurso. Possui mestrado em Letras pela Universidade de Passo Fundo (2016) e graduação em Letras - Português e Inglês pela Universidade de Passo Fundo (2013) e especialização lato sensu em Administração Escolar, Supervisão e Orientação. Atualmente além de docente da Licenciatura em Letras, é professora das áreas de língua inglesa e língua portuguesa da Universidade de Passo Fundo. É concursada da rede estadual de ensino do Rio Grande do Sul desde 2014 e, através desse concurso, desempenhou funções de professora de língua inglesa, professora de língua portuguesa, assessora e coordenadora pedagógica. Atualmente, neste vínculo, é professora de língua inglesa e língua portuguesa na E.E.E.F. Cel. Gervásio Lucas Annes. Tem experiência na área de Ensino de Língua Inglesa, Língua Portuguesa e Produção Textual, com ênfase em Linguística e na Formação de Professores, atuando principalmente nos seguintes temas: educação, ensino de línguas na escola, Base Nacional Comum Curricular, Linguística da Enunciação, desafios da escola pública, uso do livro didático, língua inglesa e formação de professores. E-mail: gabrielaprym@gmail.com

Data de submissão: set. 2020 - Data de aceite: nov. 2020 http://dx.doi.org/10.5335/rdes.v16i3.11376 


\section{Introdução}

Este texto tem o objetivo de discutir o conceito de língua em Ferdinand de Saussure e em Émile Benveniste para pensá-la na relação entre os dois linguistas, visando, a posteriori, o entendimento deste conceito em um contexto de ensino, tomando como referência a educação básica. Esta reflexão está organizada em duas partes: na primeira discutiremos o conceito de língua em Saussure e em Benveniste; a segunda diz respeito a uma reflexão a partir de Saussure, Benveniste, seus leitores sobre o conceito de língua. Essas reflexões se pautam em princípios teóricos que tomam conceitos trabalhados, principalmente, no Curso de linguística geral, de Ferdinand de Saussure, e nos Problemas de Linguística Geral I e II, de Émile Benveniste. Neste trabalho, queremos evidenciar o conceito de língua nesses autores, a fim de realizar um deslocamento teórico-metodológico para contemplar o ensino de língua portuguesa nas escolas de educação básica.

Iniciemos por uma questão posta: é inegável que o Curso de linguística geral (CLG) é um clássico. Ferdinand de Saussure e seus cursos de Linguística - ministrados em períodos de 1907, 1909 e 1910 - são referências para os estudos da linguagem. Em inúmeras situações, o linguista genebrino foi - e é - referido como "o pai da linguística".
Essa referência é natural, uma vez que Saussure e o Curso revolucionaram os estudos linguísticos do início do século XX e, até hoje, são base para diversos trabalhos de diferentes áreas do conhecimento, sobretudo nos cursos de Letras no Brasil e no mundo, colaborando sobremaneira na formação linguística de nossos professores de língua. Já dizia Isaac Salum (2012, p. 13), no prefácio à edição brasileira do CLG de 2012: "Não é [o CLG] uma 'bíblia' da Linguística moderna, que dê a última palavra sobre os fatos, mas é ainda o ponto de partida de uma problemática que continua na ordem do dia”. Portanto, também nós vamos tomá-lo como ponto de partida das considerações que faremos nestas páginas.

Assim, perguntamos: que problemática é esta que, depois de um século, ainda é atualizada? Sem dúvida, todas as questões que envolvem a língua e a linguagem. Essas questões se miscigenaram em diferentes campos de estudo da linguagem: Semiologia, Linguística da enunciação, Linguística textual, Semântica argumentativa, Semiótica discursiva, Linguística aplicada, Sociolinguística; estudos que são extremamente necessários para as reflexões sobre língua e linguagem, não apenas restritas aos muros das universidades, mas vitais para o entendimento de língua e, principalmente, para a formação de homens e 
mulheres capazes de, através da língua, se constituírem enquanto sujeitos.

Perguntamos ainda: onde tradicionalmente esses homens e mulheres iniciam suas "formações", além do meio familiar? Na escola. A constituição do homem enquanto sujeito, atribuída aos estudos enunciativos, está, inclusive, pressuposta, enquanto ideia geral, na lei maior da educação brasileira, a Lei no 9.394/1996 (BRASIL, 1996, p. 278), em seu artigo primeiro:

A educação abrange os processos formativos que se desenvolvem na vida familiar, na convivência humana, no trabalho, nas instituições de ensino e pesquisa, nos movimentos sociais e organizações da sociedade civil e nas manifestações culturais.

Assim, justificamos a necessidade de relacionarmos as teorias linguísticas com as questões vigentes no contexto educacional em que estamos inseridas, a saber: docentes de um curso de licenciatura e gestoras na educação básica. Levando isso em consideração e observando o ainda recorrente afastamento do ensino superior com a educação básica, propomos as seguintes discussões: quais as aproximações teóricas possíveis entre as perspectivas de Ferdinand de Saussure e de Émile Benveniste em relação ao conceito de língua? E, a partir disso: como essas aproximações empreendem a questão do ensino de língua portuguesa na educação básica brasileira?
Visando à resposta a esses questionamentos, realizaremos uma pesquisa bibliográfica, de cunho exploratório, tendo como marco teórico os conceitos de língua para Saussure e Benveniste e, posteriormente, as noções de língua percebidas na relação entre os dois linguistas, com base em seus leitores. Para tanto, iniciaremos a reflexão teórica deste trabalho com o conceito de língua em Saussure e Benveniste.

\section{A língua em Saussure e Benveniste}

Ferdinand de Saussure (1857-1913), linguista suíço de família nobre e revolucionário nos estudos de língua e linguagem, é reconhecido como pai da linguística moderna e precursor de muitos conceitos, posteriormente estudados por outros linguistas. É inegável a necessidade de retomar seus estudos na reflexão sobre a língua, norma das demais manifestações da linguagem e, segundo Saussure ${ }^{1}$ (2012), um sistema de signos. Assim, é preciso investigar de forma precisa os conceitos discutidos por Saussure, conforme apresentados na obra Curso de linguística geral (CLG).

Em nossa reflexão inicial, é necessário conceituar língua e a sua posição em relação à linguagem em Saussure para, posteriormente, relacioná-las aos conceitos enunciativos de Benveniste. O CLG (SAUSSURE, 2012) define a língua 
como "um princípio de classificação" e a coloca em primeiro lugar em relação aos fatos de linguagem, sendo que ela existe efetivamente na coletividade.

A linguagem tem um lado individual e um lado social, sendo impossível conceber um sem o outro. [...] a linguagem implica ao mesmo tempo um sistema estabelecido e uma evolução: a cada instante, ela é uma instituição atual e um produto do passado (2012, p. 40).

Nesse sentido, o lado social da linguagem é a língua, considerada como a norma de todas as outras manifestações da linguagem.

A língua não pode ser confundida com a linguagem. Ela é, segundo o linguista genebrino, uma parte da linguagem, uma parte essencial e social:

É [a língua], ao mesmo tempo, um produto social da faculdade de linguagem e um conjunto de convenções necessárias, adotadas pelo corpo social para permitir o exercício dessa faculdade nos indivíduos. Tomada em seu todo, a linguagem é multiforme e heteróclita. [...] ela pertence além disso ao domínio individual e ao domínio social; não se deixa classificar em nenhuma categoria de fatos humanos, pois não se sabe como inferir sua unidade (SAUSSURE, 2012, p. 41).

Assim, a língua, como produto da linguagem, é um conjunto de combinações necessárias, utilizadas por determinado grupo social, permitindo o exercício da linguagem entre os seres humanos. A linguagem, por outro lado, pertence aos dois domínios, individual e social, possui diferentes formas e não permite uma classificação ou uma categorização. Não se sabe qual a unidade da linguagem; a língua é "somente" um produto dela.

Além disso, o princípio de classificação da língua é de que ela "constitui algo adquirido e convencional, que deveria subordinar-se ao instinto natural em vez de adiantar-se a ele" (SAUSSURE, 2012, p. 41). Ou seja, a língua não é dada pela natureza como a linguagem, ela é obtida pelo ser humano. Esse fato ainda não estava claro em Saussure.

O que o linguista afirma é que "a língua não é uma instituição social semelhante às outras em todos os pontos" (SAUSSURE, 2012, p. 41), negando os preceitos de outros linguistas anteriores a ele, que se preocupavam com a comparação entre as línguas em busca de uma língua "mãe". Saussure continua refletindo que

[...] não é a linguagem que é natural ao homem, mas a faculdade de constituir uma língua, vale dizer: um sistema de signos distintos correspondentes a ideias distintas (SAUSSURE, 2012, p. 42).

Ou seja, o que é dado ao homem é a capacidade de organizar um sistema linguístico e de se comunicar através dele.

O homem poderia utilizar qualquer outro aparelho para criar e utilizar um sistema de signos, seja através de gestos ou de imagens. Não é a possibilidade de linguagem que é inata ao homem, mas sim a capacidade de inventar e utilizar um sistema organizado que proporcione a comunicação. Esse sistema é formado 
por signos linguísticos que representam diferentes ideias ou conceitos.

À língua atribui-se o primeiro lugar no estudo da linguagem, pois ela é uma faculdade mais geral que comanda e organiza os signos:

Para atribuir à língua o primeiro lugar no estudo da linguagem, pode-se, enfim, fazer valer o argumento de que a faculdade - natural ou não - de articular palavras não se exerce senão com a ajuda de instrumento criado e fornecido pela coletividade; não é, então, ilusório dizer que é a língua que faz a unidade da linguagem (SAUSSURE, 2012, p. 42).

Dessa forma, a afirmação feita anteriormente (SAUSSURE, 2012) de que a linguagem não teria unidade é, de certa forma, reconstruída por ele mesmo: A língua não é uma parte da linguagem, mas a língua faz a unidade da linguagem, no sentido de que é um instrumento criado, escolhido e utilizado pela sociedade, pelo homem que compartilha com seus semelhantes um sistema linguístico de signos.

O linguista genebrino, conforme o Curso, reflete ainda sobre as diferenças entre língua e fala, sendo esta última um ato individual que é possibilitado e possibilita processos e fenômenos psíquicos, fisiológicos e físicos. Esse circuito só é completo pela ação de pelo menos dois indivíduos. Conforme o CLG, o sempre individual constitui-se como parole (fala).
Se pudéssemos abarcar a totalidade das imagens verbais armazenadas em todos os indivíduos, atingiríamos o liame social que constitui a língua. Trata-se de um tesouro depositado pela prática da fala por todos os indivíduos pertencentes à mesma comunidade, um sistema gramatical que existe virtualmente em cada cérebro ou, mais exatamente, nos cérebros dum conjunto de indivíduos, pois a língua não está completa em nenhum, e só na massa ela existe de modo completo (SAUSSURE, 2012, p. 45).

Essas individualidades, quando atingem o social, constituem a língua. A língua é um sistema que existe em cada ser de determinada comunidade. Sendo assim, ela só existe na coletividade de um modo completo. Saussure, no Curso (2012), caracteriza a língua como social e essencial em relação à fala, que é acessória e individual. O linguista apresenta as características da língua, opondo-a à linguagem e à fala:

Recapitulemos os caracteres da língua:

$1^{\circ}$ Ela é um objeto bem definido no conjunto heteróclito dos fatos da linguagem. [...]

$2^{\circ}$ A língua, distinta da fala, é um objeto que se pode estudar separadamente. [...]

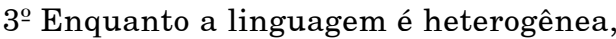
a língua assim delimitada é de natureza homogênea: constitui-se num sistema de signos [...].

$4^{\circ} \mathrm{A}$ língua, não menos que a fala, é um objeto de natureza concreta, o que oferece grande vantagem para seu estudo [...] (SAUSSURE, 2012, p. 46).

Resumindo, segundo o Curso, a língua é um conceito bem definido entre os vários pertencentes às reflexões sobre 
linguagem; a língua pode ser estudada separadamente em relação à fala e aos demais processos de linguagem. A língua, enquanto sistema de signos utilizado por determinada comunidade, é uma só. Essa homogeneidade, assim como sua natureza concreta, apresenta vantagem para o seu estudo.

Isso evidencia com a concepção de língua como "sistema de signos que exprimem ideias" e a delimita no "conjunto dos fatos de linguagem, classificável entre os fatos humanos" (SAUSSURE, 2012, p. 47). Nesse sentido, é necessária a concepção de uma ciência que estuda a vida dos signos, inseridos no "seio da vida social”. Esse uso social dos signos ocorre através da língua, e a ciência que se preocupa com tais funcionamentos é a Semiologia.

Isso nos traz à necessidade de pontuar, aqui, uma consideração: a diferença entre a Linguística e a Semiologia é que a primeira se preocupa com a língua entre os sistemas semiológicos e, segundo o Curso (SAUSSURE, 2012, p. 48), "não é senão uma parte dessa ciência geral (semiologia)". Para o linguista, a tarefa de determinar o lugar e refletir sobre a Semiologia como uma ciência geral dos signos cabe à Psicologia Geral e à Social; e a segunda, no início do século XX e para os estudos saussurianos, era uma ciência que ainda não existia. ${ }^{2}$

Posteriormente, no CLG, há noções diversas e específicas em relação ao signo linguístico. O que nos interessa é compreender como o signo se comporta em relação à língua, inclusive em relação ao tempo. "De fato, nenhuma sociedade conhece nem conheceu jamais a língua de outro modo que não fosse como um produto herdado de gerações anteriores e que cumpre receber como tal" (SAUSSURE, 2012, p. 112). Para uma modificação do sentido de um signo e do sistema linguístico ser possível, é necessário que a mudança seja aceita pela coletividade, levando em consideração que a língua pertence, ao mesmo tempo, ao social e ao individual. Apesar de o tempo ser responsável por assegurar a continuidade da língua, é por meio dele que a língua pode se alterar:

Um dado estado de língua é sempre o produto de fatores históricos, e são esses fatores que explicam por que o signo é imutável, vale dizer, por que resiste a toda substituição. Mas dizer que a língua é uma herança não explica nada, se não se for mais longe. Não se podem modificar, de um momento para o outro, leis existentes e herdadas? Essa objeção nos leva a situar a língua em seu quadro social e formular a questão como o faríamos para as outras instituições sociais. Como se transmitem instituições? Cumpre, primeiramente, avaliar a maior ou menor liberdade de que desfrutam as outras instituições; ver-se-á que para cada uma delas existe um equilíbrio diferente entre a tradição imposta e a ação livre da sociedade [...] (SAUSSURE, 2012, p. 112).

Além de se modificar através do tempo, a língua, como sistema de signos, possui um caráter complexo: noções como arbitrariedade e valor do signo 
têm relação direta com o tempo, sendo que o signo, assim como a língua, se remodela dependendo das necessidades de seus usuários. Nesse sentido, exige-se um equilíbrio entre essas mudanças, de ação livre da comunidade linguística, e a tradição herdada de fatores históricos.

De acordo com as reflexões de Saussure consideradas no CLG (2012), há dois eixos através dos quais se situam objetos de todas as ciências e, mais especificamente, da linguística: o eixo das simultaneidades, "concernente às relações entre coisas coexistentes, de onde toda intervenção do tempo se exclui" (2012, p. 121), e o eixo das sucessões, "sobre o qual não se pode considerar mais que uma coisa por vez, mas onde estão situadas todas as coisas do primeiro eixo com suas respectivas transformações" (2012, p. 121). Posteriormente, esses eixos foram chamados - por seus leitores -, respectivamente, de eixo do paradigma e eixo do sintagma. Quando reflete sobre sintagma e paradigma, Saussure apresenta uma nova noção de língua: "a língua constitui um sistema de valores puros que nada determina fora do estado momentâneo de seus termos" (2012, p. 122).

Alguns dos estudiosos posteriores a Saussure focalizaram suas análises no princípio de classificação da língua e não na sua existência pela coletividade. Em algumas práticas de ensino, por muito tempo - e até hoje -, a língua é considerada apenas como sistema de classificação, não estando à disposição do homem que a coloca em uso.

A língua, para Saussure, é um tesouro compartilhado entre indivíduos, um conjunto definido, a parte social da linguagem, um sistema de signos, um objeto de natureza concreta. O linguista se preocupou em estudar a língua como um sistema de signos organizados e relacionados entre si, um sistema que conhece somente sua própria ordem ${ }^{3}$, de forma e não de substância, a qual constitui o único e verdadeiro objeto da Linguística (SAUSSURE, 2012).

Como precursor da linguística moderna, Saussure atribui à língua um conceito de sistema de signos que se organizam e se relacionam entre si. Anos mais tarde, outro estudioso de questões da língua e da linguagem retoma o pai da linguística em seu estudo, mas, de certa forma, ultrapassa seus preceitos ao relacionar a língua com o homem que a utiliza para viver e se comunicar com outro homem em sociedade, colocando em pauta, nos estudos linguísticos, a perspectiva da enunciação. Trazemos, então, Émile Benveniste e o seu conceito de língua, discutido em diferentes momentos de sua obra.

Benveniste é o linguista da enunciação que mais se aproxima de Saussure, relacionando a língua com o ato enunciativo. Trazemos aqui um primeiro recorte para a discussão: o texto "A forma e o 
sentido na linguagem", produzido em 1967 e destinado a um grupo de filósofos. Nele, ao apresentar sua visão de signo e das relações entre a forma e o sentido na linguagem, Benveniste retoma Saussure, mas não se limita às suas noções.

Além disso, a escolha deste recorte, que leva em consideração o texto de 1967, se justifica pelas palavras do próprio Benveniste, que manifesta no texto a intenção de ultrapassar Saussure: "Compete-nos tentar ir além do ponto a que Saussure chegou na análise da língua como sistema significante" (BENVENISTE, 1989, p. 224). Para nós, há dois motivos importantes para refletir sobre "A forma e o sentido na linguagem": a comprovação de que Benveniste leu e refletiu sobre Saussure, apresentando isso no texto, e a manifestação de suas reflexões acerca da língua:

Numa primeira aproximação, o sentido é a noção implicada pelo termo mesmo da língua como conjunto de procedimentos de comunicação identicamente compreendidos por um conjunto de locutores; e a forma é, do ponto de vista linguístico (bem distinto do ponto de vista dos lógicos), ou a matéria dos elementos linguísticos quando o sentido é refletido ou o arranjo formal destes elementos ao nível linguístico do qual depende. Opor a forma ao sentido é uma convenção banal e os próprios termos parecem assim gastos mas se nós tentarmos reinterpretar esta oposição no funcionamento da língua integrando-a e esclarecendo-a, ela retoma toda a sua força e sua necessidade; [...] bem antes de servir pra comunicar, a linguagem serve para viver. [...] o próprio da linguagem é, antes de tudo, significar (BENVENISTE, 1989 , p. 222, grifo do autor).
Benveniste comprova que é necessário deixar de ver forma e sentido como opostos; eles devem ser percebidos como elementos que constituem a língua. Assim sendo, o linguista defende que a linguagem (e a língua como parte dela) serve para muito além de comunicar ela serve para viver. Essa belíssima citação remete a um caráter social e filosófico da linguagem que proporciona ao homem a capacidade de se comunicar e, através dela, viver em sociedade. Benveniste ainda afirma que a significação é importante e é própria da linguagem, que significa por si própria, ou seja, não necessita de nenhuma outra atividade para significar. E, nessa reflexão, retoma Saussure:

Diremos, como Saussure, a título de primeira aproximação, que a língua é um sistema de signos. É a noção de signo que, doravante, integra no estudo da língua a noção muito geral de significação. Esta definição a coloca exatamente, inteiramente? Quando Saussure introduziu a ideia de signo linguístico, ele pensava ter dito tudo sobre a natureza da língua; não parece ter visto que ela podia ser outra coisa ao mesmo tempo, exceto no quadro da oposição bem conhecida que ele estabelece entre língua $\mathrm{e}$ fala. Compete-nos tentar ir além do ponto a que Saussure chegou na análise da língua como sistema significante. (BENVENISTE, 1989, p. 224).

O linguista ratifica que, ao introduzir a ideia de signo, Saussure pensou dizer tudo sobre a natureza da língua, lembrando que, para o mestre genebrino, a língua era um sistema de signos. Ben- 
veniste sustenta que a língua é feita de signos, sendo eles unidades semióticas que possuem um limite interior, o da significação. "É então signo a unidade assim definida, dependente da consideração semiótica da língua" (BENVENISTE, 1989, p. 225). O conceito de signo é essencial para o entendimento da língua, tanto para Saussure quando para Benveniste.

A partir deste momento, em "A forma e o sentido na linguagem", Benveniste inicia uma reflexão em relação ao signo que não nos interessará por se tratar do signo como unidade. Essa relação entre os signos faz com que eles tenham existência através do uso da língua:

[...] a noção de uso e de compreensão da língua como um princípio de discriminação, um critério. É no uso da língua que um signo tem existência; o que não é usado não é signo; e fora do uso o signo não existe. [...] ou está na língua, ou está fora da língua (BENVENISTE, 1989, p. 227).

Isto é, a existência e o sentido de um signo só são possíveis através do uso da língua: ou um signo é utilizado por seus falantes e pertence à língua ou está fora dela e não é mais signo. De acordo com Flores (2013, p. 140), “o sentido do signo, unidade do domínio semiótico, é definido como o uso que os falantes fazem ele, uso este reconhecido intralinguisticamente". Ou seja, o sentido do signo é determinado pelo uso e pelo reconhecimento deste uso na língua enquanto sistema.

Segundo Benveniste (1989, p. 229), "há para a língua duas maneiras de ser língua no sentido e na forma [...] a língua como semiótica [...] a língua como semântica”. O linguista ainda declara que a modalidade de significar tem relação com a semiótica, e a modalidade de comunicar, com a semântica:

A noção de semântica nos introduz no domínio da língua em emprego e em ação; vemos desta vez na língua sua função mediadora entre o homem e o homem, entre o homem e o mundo, entre o espírito e as coisas, transmitindo a informação, comunicando a experiência, impondo a adesão, suscitando a resposta, implorando, constrangendo; em resumo, organizando toda a vida dos homens. É a língua como instrumento da descrição e do raciocínio. Somente o funcionamento semântico da língua permite a integração da sociedade e a adequação ao mundo, e por consequência a normalização do pensamento e o desenvolvimento da consciência (BENVENISTE, 1989, p. 229).

A expressão semântica - que possibilita a comunicação - é a frase, atualizada linguisticamente pelo pensamento do locutor que coloca a língua em ação. "Com o signo tem-se a realidade intrínseca da língua; com a frase liga-se às coisas fora da língua [...], o sentido da frase implica referência à situação de discurso e à atitude do locutor" (BENVENISTE, 1989, p. 230). Eis a perspectiva do discurso. A frase está no discurso. Já não temos mais o signo enquanto unidade de valor, mas como unidade integrante da frase que se realiza no discurso.

O sentido da frase é, portanto, a ideia que ela exprime, que se realiza pela escolha e organização sintática de palavras, 
"pela ação que elas exercem uma sobre as outras [...] uma frase participa sempre do aqui e agora" (BENVENISTE, 1989, p. 230, grifos nossos). Assim sendo, a frase como ideia, como sentido, existe pela decisão de um locutor que a utiliza em um aqui e um agora. Na frase também há enunciação.

Benveniste (1989, p. 231) continua: "O sentido de uma frase é outra coisa diferente do sentido das palavras que a compõem. O sentido de uma frase é sua ideia, o sentido de uma palavra é seu emprego (sempre na acepção semântica)". Sobre as noções citadas, reflete Flores (2013, p. 142, grifos do autor):

Observe-se que o termo frase tem seu sentido consideravelmente ampliado nessa parte do artigo A forma e o sentido na linguagem. Frase é entendida não como proposição, mas como produção de discurso. Benveniste chega a dizer que "a frase é então cada vez um acontecimento diferente; ela não existe senão no instante em que é proferida e se apaga neste instante; é um acontecimento que desaparece" (PLG II:231), definição esta muito próxima da de enunciação. Nessa ocorrência de frase eu não hesitaria em coloca-la em relação de sinonímia com enunciação.

Além do mais, conforme o Dicionário de linguística da enunciação, é com a frase - como conceito em Benveniste - que passamos de um sistema para o outro: "da língua como sistema de signos para a língua em ação, no discurso, no modo semântico de significância da língua” (FLORES et al., 2009, p. 127). Isso quer dizer que é a frase em uso que coloca a língua em ação, transformando-a de um sistema de signos a um modelo de significância.

Dessa forma, assim como consolidado por Flores (2013), importante estudioso da enunciação e de Benveniste, o signo está ligado à existência da língua e à frase pelo uso discursivo dela; a forma se explica por si só, e o sentido diz respeito às relações com outros signos da língua - relação essa que pode se dar na frase. Para Flores (2013, p. 61), “é o conjunto de falantes de uma língua que determina se um signo tem ou não sentido". O sentido do signo é, portanto, definido pela coletividade.

O segundo texto escolhido para nossa reflexão em relação ao conceito de língua para Benveniste é "Semiologia da língua”, já que o estudo dos sistemas de signos é muito importante para o conceito de língua e, posteriormente na pesquisa de doutoramento, para uma reflexão sobre escrita. Publicado em 1969, o artigo apresenta os dois modos de ser língua, o modo semiótico e semântico, além de manifestar relações com Saussure. Conforme Flores (2013, p. 61, grifos do autor):

Em Semiologia da língua (1969), por motivos evidentes já no título do artigo, o termo signo comparece como o mais recorrente [...]. O interesse de Benveniste, nesse texto, é verificar o que há na língua que a singulariza frente a todos os demais sistemas semiológicos [...]. Semiologia da língua é, seguramente, se não o mais complexo texto de Benveniste, aquele que levanta maiores problemas [...]. 
A complexidade do texto já é visível nas primeiras linhas, em que Benveniste (1989, p. 43) questiona, problematizando: "Qual é o lugar da língua entre os sistemas de signos?". Para responder a essa pergunta, o linguista busca estudiosos da linguística anteriores a ele: Charles Peirce e Ferdinand de Saussure. Ao último, dedica referência na única epígrafe presente no PLG I e no PLG II.

A respeito de Peirce (1839-1914), Benveniste (1989, p. 44) afirma: "A língua se reduz, para ele [Peirce], às palavras, e estas são igualmente signos, mas elas não são do domínio de uma categoria distinta ou mesmo de uma espécie constante". Em todo o texto, o linguista da enunciação se afasta do americano ao criticar o lugar do signo como "base do universo inteiro" e como princípio de explicação para "tudo". Para Benveniste, a língua tem lugar diferenciado, ao contrário do que considerou Peirce em seus estudos do signo.

Ao distanciar-se de Peirce, Benveniste se aproxima de Saussure, pontuando conceitos que lhe são caros. O "pai da linguística" falou de uma Semiologia - em relação à Linguística - que se preocupa com o signo linguístico. Essas reflexões justificam a referência de Benveniste a Saussure, que fica clara inclusive com citações diretas do CLG sobre a tarefa da linguística: "1. descrever sincronicamente e diacronicamente todas as línguas conhecidas; 2 . depreender as leis gerais que operam nas línguas; 3 . delimitar-se e definir-se a si mesma" (BENVENISTE, 1989, p. 45).

A noção saussuriana do objeto da linguística é baseada em princípios de unidade e classificação, o que serve de início para uma noção de semiologia:

Por um só gesto, Saussure define o objeto da linguística - funda-a, portanto - e confere certo estatuto aos conjuntos dos fatos humanos. E qual o fundamento disso? A noção de signo linguístico. É pela noção de signo que estão vinculadas linguística e semiologia: "Onde a língua acha sua unidade e o princípio de seu funcionamento? Em seu caráter semiótico. Por este se define sua natureza, por este também ela se integra num conjunto de sistemas de mesmo tipo" (PLG II:49) (FLORES, 2013, p. 149).

A percepção semiótica dos fatos humanos é realizada através do signo. É por esse motivo que Benveniste tem preferência por Saussure, pois "[...] a semiologia se modela sobre a linguística [...]" (FLORES, 2013, p. 149, grifo do autor). É este o objetivo do texto de 1969: apresentar o caráter semiológico da língua. Benveniste (1989, p. 49) continua, afirmando que é no seu caráter semiótico que a língua acha a sua unidade e o princípio de seu funcionamento.

Na opinião de Saussure, a língua é o sistema mais importante daqueles que são sistemas de signos. Saussure pouco relaciona Linguística com Semiologia, segundo a visão de Benveniste. E é pensando na relação entre os sistemas e o objeto da Semiologia que o linguista da 
enunciação termina a primeira parte de seu texto, publicado nos anais do evento Semiótica 1. A segunda parte do texto, apresentada no congresso Semiótica 2, expõe outras complexidades. É difícil dedicar um estudo breve - como o feito aqui - ao texto "Semiologia da língua"; sua profundidade merece grandes investigações, que são feitas por estudiosos conceituados de Benveniste.

Nesse segundo momento do texto, o linguista reflete sobre outros sistemas semiológicos - poesia e música, por exemplo. Entretanto, para nós, o que interessa é pensar o aspecto semiológico da língua: "Os signos, para nascerem e se estabelecerem como sistema, supõem a língua, que os produz e os interpreta" (BENVENISTE, 1989, p. 51). Há, inegavelmente, outros sistemas de signos - entre eles a escrita -, mas é necessário compreender que a língua é o mais importante deles, pois é a partir dela que os outros sistemas existem ou são interpretados.

Entre os sistemas semiológicos não há "sinonímia", ou seja, "não se pode dizer a mesma coisa pela fala e pela música" (BENVENISTE, 1989, p. 53). Ambos os sistemas possuem bases diferentes. A base da língua é o signo, produzido e interpretado por ela. "A língua ocupa uma situação particular no universo dos sistemas de signos. Se se convenciona designar por $\mathrm{S}$ o conjunto desses sistemas e L a língua, a conversão se faz sempre no sentido $\mathrm{S}->\mathrm{L}$, nunca o inverso" (BENVENISTE, 1989, p. 55). A língua é, portanto, um dos sistemas de signos existentes no mundo. É o mais importante deles.

Todos os sistemas semiológicos possuem como unidade um signo; o da música, por exemplo, é o som. O signo é uma unidade, mas uma unidade pode não ser um signo. A língua possui e é constituída por unidades, e essas unidades são, sim, signos. Nesse sentido, o que atribui à língua um lugar especial entre os outros sistemas de signos? "[...] a língua é o interpretante de todos os outros sistemas, linguísticos e não-linguísticos [...] a língua pode, em princípio, tudo categorizar e interpretar, inclusive ela mesma" (BENVENISTE, 1989, p. 61-62, grifo nosso). De que forma se explica e interpreta uma partitura musical, por exemplo? Através da língua. Além disso, a língua é o único sistema que possui a dupla significância dos modos semiótico e semântico. Ademais, é uma grande organização semiótica, pois:

$1^{\circ}$. ela se manifesta pela enunciação, que contém referência a uma situação dada; falar, é sempre falar-de;

$2^{\circ}$. ela consiste formalmente de unidades distintas, sendo que cada uma é um signo;

$3^{\circ}$. ela é produzida e recebida nos mesmos valores de referência por todos os membros de uma comunidade;

$4^{\circ}$. ela é a única atualização da comunicação intersubjetiva (BENVENISTE, 1989, p. 63). 
A língua é o sistema que torna possível a existência humana e a organização em sociedade; há nela, além de relações semióticas e semânticas, sociológicas. Resumindo, a língua é manifestada pela enunciação, ou seja, pelo uso; a língua é composta por unidades de significância, os signos; ela é compartilhada pelos membros de determinada comunidade; ela existe pela relação comunicativa entre sujeitos. Nesta noção, Benveniste vai além de Saussure - para quem o signo tem valor. Para ele, o signo tem significância no uso, no discurso.

Benveniste (1989, p. 66) adianta que “o privilégio da língua é de comportar simultaneamente a significância dos signos e a significância da enunciação". Isto é, o que diferencia a língua entre os demais sistemas de signos, é a capacidade de ter sentido na sua unidade - o signo linguístico - e no seu uso - a enunciação.

Saussure definiu a língua como sistema de signos; Benveniste vai além na reflexão. O que os diferencia? Benveniste considera que não se pode atribuir ao signo o princípio singular da língua em seu funcionamento discursivo, no uso: "Para o que denominamos semiótico, a teoria saussuriana do signo linguístico servirá de base à pesquisa. $\mathrm{O}$ domínio semântico, ao contrário, deve ser reconhecido como separado. Ele precisará de um aparelho novo de conceitos e definições" (BENVENISTE, 1989, p. 67). Seria este aparelho de domínio semântico o da enunciação?
Para responder à pergunta, Benveniste (1989, p. 67) afirma que é necessário ultrapassar Saussure:

Em conclusão, é necessário ultrapassar a noção saussuriana do signo como princípio único, do qual dependeriam simultaneamente a estrutura e o funcionamento da língua. Esta ultrapassagem far-se-á por duas vias:

- na análise intralinguística, pela abertura de uma nova dimensão de significância, a do discurso, que denominados semântica, de hoje em diante distinta da que está ligada ao signo, e que será semiótica;

- na análise translinguística dos textos, das obras, pela elaboração de uma metassemântica que se construirá sobre a semântica da enunciação.

Benveniste vai além de Saussure em dois caminhos: primeiramente de forma intralinguística, considerando o modo semântico como processo de significância e o plano enunciativo como discurso; o segundo é a via translinguística, como reflexão com base em grandes obras, no texto como um todo. Essa translinguística é feita através de uma metassemântica que, para Flores (2013, p. 154), é "parte da semântica da enunciação". Registramos, nós, que há muito ainda o que dizer e fazer. Esta é a base para a próxima reflexão: as noções de língua em Saussure e, em um recorte, para Benveniste, nos proporcionam um caminho que visa à relação entre os dois linguistas ao construirmos o conceito de língua em uma perspectiva de ensino. 


\section{Saussure, Benveniste, seus leitores e a língua em um contexto de ensino}

A partir das noções de língua trazidas por Saussure e Benveniste e levando em consideração a inegável relação entre os dois linguistas, nesta seção, nos dedicaremos a pensar os conceitos de língua na compatibilidade entre os dois teóricos. Para isso, buscamos, em leitores de Saussure e Benveniste, questões já ditas que podem ser de interesse para o entendimento da língua em um contexto de ensino.

No decorrer da seção anterior, uma questão foi posta: pensar em língua para Saussure e Benveniste é pensar em sistema:

[...] a língua tem definição autônoma, é vista como sistema, é norma para todas as manifestações da linguagem, portanto, pode ser estudada cientificamente. A língua é só uma parte da linguagem, é seu produto social e, como tal, é compartilhada pela comunidade de fala por meio de um contrato que se estabelece entre seus membros; é o produto que o indivíduo registra passivamente por aprendizagem, é de natureza concreta.

A fala - o outro aspecto da linguagem - é a utilização da língua, sua parte individual, de caráter criador e livre. É o acessório, o acidental da linguagem. [...]. A fala se subordina à língua .

A língua pode ser estudada separadamente, mas língua e fala são estreitamente relacionadas: a língua é necessária para a fala inteligível, e a fala é necessária para o estudo da língua. A fala vem antes, fez evoluir a língua. Há interdependência entre elas (BARBISAN; FLORES, 2009, p. 10, grifos dos autores).
Conforme Barbisan e Flores (2009), com base em Saussure, referir-se a língua é levar em consideração que esta é vista como sistema, é produto social da linguagem, é compartilhada pelos indivíduos. A fala, também como parte da linguagem, é o uso individual da língua, é subordinada a ela. Língua e fala são diretamente associadas e há interdependência entre elas. Saussure e Benveniste levam língua e fala em consideração; para Benveniste, língua e fala não estão em oposição. Saussure prioriza a língua, Benveniste leva a fala em consideração ao relacioná-la como uso, como discurso, como produtora de significação. Estes conceitos são importantes para pensarmos o ensino da língua materna na escola que idealmente percebe como cerne das aulas de língua as situações de uso.

Benveniste, segundo Barbisan e Flores (2009), mostra que a linguagem é a atividade significante por excelência e que a significação não é algo acrescentado à língua, é constituinte da língua. A fala, ou seja, o uso da língua, segundo Benveniste, está subordinado ao sentido. "É no uso da língua que um signo tem existência" (BENVENISTE, 2005, p. 222). O signo, enquanto unidade de sentido de um sistema, é o que constitui a língua.

Segundo Benveniste, que vai além de Saussure, há duas formas de ser língua: o sistema semiótico, da organização dos signos, e o sistema semântico, da 
língua em uso na comunicação. Na base dessas noções, está o poder significante da língua:

O emprego da língua é um mecanismo relativo a toda a língua através da enunciação, da qual o discurso é uma manifestação. Mas o discurso não é a fala de Saussure, que Benveniste interpreta como sendo a produção do enunciado. A enunciação, adverte ele [Benveniste], é o ato de produzir o enunciado. A lingua é o instrumento de que se utiliza o locutor para se enunciar e produzir o discurso. Pela enunciação a língua se converte em discurso (BARBISAN; FLORES, 2009 , p. 16, grifos dos autores).

É nesta perspectiva que Benveniste vai além de Saussure, e é esse entendimento de língua que é necessário na escola. A escola pode (ou deve?) ser o lugar que proporciona estes dois entendimentos de língua: a compreensão da língua enquanto sistema que está à disposição do aluno e a língua que, através da enunciação, se converte em discurso. Precisamos, no trabalho com a língua na escola, compreender claramente que o aluno se apropria da língua enquanto sistema (de seu aparelho formal) e se enuncia. É a apropriação da língua que coloca o locutor em seu discurso.

Além disso, o próprio signo linguístico é dependente da possibilidade de uso da língua. É paradoxal pensar que o signo só existe no uso da língua e que a língua só é língua porque é um sistema de signos. Toda esta noção possui um denominador comum: o sujeito, aquele que enuncia, aquele que usa a língua para se relacionar com ele mesmo, com os outros e com o mundo. A noção de valor, já trazida por Saussure, em Benveniste, decorre, de forma inerente ao sistema da língua, da influência que o uso tem sobre esse sistema:

É no uso da língua que um signo tem existência; o que não é usado não é signo; e fora do uso o signo não existe. Não há estágio intermediário; ou está na língua, ou está fora da língua, "tertium non datur" (BENVENISTE, 1989, p. 227).

Assim, Benveniste desenvolve uma teoria de significação, a partir de seu "encontro" com Saussure. Recorremos aos estudos de Claudine Normand que assume um encontro entre Saussure e Benveniste. Diz Normand (2009, p. 159-160, grifos da autora):

Os dois processos, linguístico e filosófico, coexistem de fato depois de 1964, ligados pelo jogo de dois desdobramentos em torno de três termos vizinhos: primeiro desdobramento: a análise do sistema de signos, dita desde 1966 semiótica, é acompanhada em uma análise do discurso, dita semântica; mas, segundo desdobramento: o segundo elemento dessa dupla análise linguística, é chamado a se prolongar em um vasto programa com limites indefinidos, próximo de uma antropologia cultural, que Benveniste resume sob o termo semiologia, e precisa na ocasião pelo termo metassemântica.

Conforme Normand (2009, p. 160), Benveniste, na fase de sua produção em que apresenta a reflexão sobre "pessoa", se preocupa em "aplicar o método saussuriano a todas as descrições concretas, jamais separando forma e 
sentido; tentar, nesse caso, apreender o papel da significação na língua; ampliar essas marcas à uma teoria do sentido e do sujeito [...]". Nestes momentos, e na "ultrapassagem", Benveniste formula uma "nova linguística": a linguística do uso, do discurso, a do semântico, e da do sistema da língua, a semiótica.

Ainda segundo Normand (2009, p. 166, grifos da autora),

[...] se seguirmos a divisão semiótica/semântica, solidamente reafirmada em 1969, esses termos objetivos diriam respeito, de um lado, ao estudo semiótico, enquanto elementos do sistema, de outro, ao estudo semântico na medida em que constituem frases, mensagens, discurso, pelos quais a língua é colocada em uso.

Parece-nos claro que esse é o trabalho com a língua na escola: de um lado, o manejo da língua enquanto sistema de signos, as análises morfológicas, as relações sintáticas, os sentidos; de outro, todas essas noções aplicadas na constituição de frases, mensagens, na atribuição da língua em uso, enquanto discurso. É, portanto, na ultrapassem que Benveniste faz de Saussure que se constitui a importância do conceito de língua nos contextos de ensino. Essa noção é necessária para o professor de educação básica ao trabalhar com a língua, e para o professor das licenciaturas ao compartilhar esse entendimento com os futuros professores.

Dessa maneira, Benveniste vai além de Saussure não apenas em relação à significação, mas também no desenvolvimento da Semiologia geral:

[É preciso lembrar os linguistas que] seu objeto, a língua, é informado de significação, que é por isso que é estruturado, e que esta condição é indispensável ao funcionamento da língua entre os outros sistemas de signos (NORMAND, 2009, p. 174).

Portanto, percebemos que a língua enquanto sistema, para Benveniste, só tem valor se estiver ligada ao sentido e ao uso. Conforme Normand (2009, p. 175), é aí em "[...] que ele [Benveniste] é saussuriano e realmente vai mais longe já que parece estabelecer uma relação de necessidade entre sentido e forma".

Benveniste se refere explicitamente a Saussure para retomar a semiologia no sentido de ciência geral dos sistemas de signos; no entanto, fica difícil, como vimos anteriormente, fixar o que ele entende por semiologia, termo que parece designar duas perspectivas e dois objetivos bastante distintos: em um primeiro emprego, $a$ semiologia retoma o programa saussuriano de "ciência geral dos sistemas de signos ${ }^{6 ”}$; em um segundo emprego, uma semiologia parece designar o conjunto constituído pelas duas análises, semiótica e semântica, aplicadas a um determinado domínio (por exemplo, $a$ semiologia da língua) (NORMAND, 2009, $\mathrm{p}$. 178-179, grifos da autora).

É inegável, portanto, que há uma relação entre Saussure e Benveniste. Normand (2009, p. 197-198) apresenta cinco tipos de discurso sobre a relação entre Saussure e Benveniste: o da filiação, o da novidade, o da comparação, o discurso em relação à interdisciplinaridade e o 
em relação à instituição universitária. Sobre esses apontamentos de Normand, Flores e Teixeira (2009, p. 76) concluem: Benveniste é o mais saussuriano dos linguistas.

A distinção entre sistema e estrutura é cara a Benveniste e, em seus trabalhos relativos à enunciação, encontramos grande ênfase na noção de sistema, a única realmente utilizada por Saussure. Para os trabalhos sobre enunciação é o conceito de sistema que mais interessa a Benveniste, mesmo que, para os trabalhos ligados ao comparativismo, percebamos forte influência da noção pós-saussuriana de estrutura (FLORES; TEIXEIRA, 2009, p. 80, grifos dos autores).

O sentido da língua se constrói a partir das acepções da fala (enquanto uso). Além disso, para Benveniste, há uma interdependência entre langue e parole: partimos dos fatos da parole para atingir o sistema da langue (FLORES; TEIXEIRA, 2009). Esse princípio está claro no trabalho com a língua na escola: partimos de situações reais de uso da língua (parole) para tornar possível uma reflexão sobre a língua enquanto sistema de signos (langue). Esse é um trabalho com a língua possibilitado através de documentos norteadores como a BNCC. Se essa noção, atualmente, está presente na prática docente na educação básica, não temos certeza.

Normand (2009) e Flores e Teixeira (2009) vão além: um signo, assim como seu sentido, depende de que ele possa ser usado pelos sujeitos que utilizam a língua.
Em Benveniste, o significado do signo linguístico comporta a noção de uso da língua, logo o valor, inerente ao sistema que é, decorre da influência que o uso tem sobre esse sistema (FLORES; TEIXEIRA, 2009, p. 81, grifo dos autores).

Essa percepção é essencial para o trabalho com a língua na escola.

Onde está, portanto, a ultrapassagem de Benveniste em relação à Saussure?

A teoria saussuriana do valor foi relida por Benveniste a partir da ideia de uso. [...]. Em Benveniste, não se trata mais de distinguir língua e fala, mas de ver que a língua comporta a fala e vice-versa [...] [o que é dito, talvez, de forma embrionária no Curso] [...]. [...]. Se Saussure concedia à língua um status de maior relevância, Benveniste coloca de novo a fala na ordem do dia. E é o próprio Saussure quem autoriza este olhar, ao conceber a língua e a fala como dois planos constituintes da linguagem. A ideia de conceber um lugar em que ambas estejam integradas já está em Saussure.

Admitido esse raciocínio, o objeto da linguística de Benveniste aparece como não redutível à língua como sistema, mas também não identificado à fala como o uso individual do sistema (FLORES; TEIXEIRA, 2009, p. 82, grifos dos autores).

O mesmo se dá com o trabalho com a língua em contextos de ensino: se ensina gramática e análises morfossintáticas (idealmente não de forma isolada, mas a serviço do uso) para que o aluno coloque em uso o sistema da língua e os sentidos que nele se produzem. Esse uso tem como produto o discurso e os textos orais e escritos. A relação entre o aluno e outro aluno e entre o aluno e o mundo se dá 
por meio de sistemas de signos, como a língua e a escrita.

Assim, quanto mais produtivo for o trabalho com a língua na escola, mais oportunidades os alunos terão de se relacionarem uns com os outros e com o mundo de forma igualitária. $\mathrm{O}$ trabalho docente deve tomar a língua e analisá-la no seu funcionamento. Os estudantes-leitores (da e com a língua) precisam ser capazes de entender que ao colocar a língua em funcionamento, tornam-se sujeitos de seu dizer porque sabem manejá-la, forjá-la, usá-la para expressarem o que pensam do e no mundo. Acreditamos que ensinar língua portuguesa na escola significa ensinar a usar a língua nas situações mais diversas em que a enunciação se impõe entre falantes de uma língua. Eis uma fragilidade: isso nem sempre acontece nas salas de aula da educação básica. Talvez porque a escola não ofereça condições; talvez porque os estudantes estejam "difíceis"; talvez porque estamos vivendo uma crise no que respeita a função da escola na sociedade atual; talvez porque falte o conhecimento de uma teoria linguística aos professores que possibilite uma abordagem outra do texto em suas aulas de língua maternal; talvez porque necessitemos de uma verdadeira e significa análise da língua em textos. Para encerrar esta reflexão, propomos um questionamento: o que significa pensar o trabalho com e de língua em sala de aula, a partir de uma concep- ção enunciativa de língua? Destacamos ainda que discutir ensino de língua materna implica trazer presente o conceito (enunciativo) de língua. Na perspectiva de Émile Benveniste, a língua, enquanto sistema, expressa o que queremos dizer, transformando-se em linguagem. Benveniste afirma que a língua se organiza como uma grande estrutura, portadora de estruturas menores e de muitos níveis. Assim, as formas da língua, relacionadas em diferentes níveis, arquitetam o texto e apontam o que deve ser lido. $\mathrm{E}$ isso deve ser ensinado nas mais diversas e diferentes atividades realizadas na sala de aula de língua portuguesa na escola. O conceito de língua, tomado numa perspectiva enunciativa, deve organizar as propostas de trabalho de uma sala de aula da educação básica.

\section{Considerações finais}

Este artigo teve a seguinte orientação de trabalho: a proposta de uma discussão sobre o conceito de língua em e na relação entre Saussure e Benveniste, bem como as possibilidades de entendimento desse conceito em um contexto de ensino. Ele foi organizado em duas partes teóricas: a língua em Saussure e Benveniste e Saussure, Benveniste, seus leitores e o conceito de língua em um contexto de ensino.

Ao finalizarmos este trabalho, percebemos que há, sem dúvidas, encontros em Saussure e Benveniste e que a relação 
entre eles está marcada pela ultrapassagem realizada por Benveniste ao ampliar a noção de significação e ao levar em consideração o sentido e a língua em sua dependência do uso realizado pelos falantes.

Além das perspectivas trazidas por Saussure sobre a língua enquanto sistema de signos, Benveniste nos apresentou a noção de que há duas formas de ser língua: o semiótico e o semântico. Percebemos, com as leituras realizadas neste artigo e com nossa experiência docente, que essa é uma perspectiva possível para o trabalho com a língua na escola: de um lado, o trabalho da língua enquanto sistema de signos, as análises morfológicas, as relações sintáticas, os sentidos; de outro (mas em relação com o anterior), todas essas noções aplicadas na constituição de frases, mensagens, na atribuição da língua em uso, enquanto discurso.

É, dessa maneira, na ultrapassagem que Benveniste faz de Saussure que se constitui a importância do conceito de língua nos contextos de ensino. Essa noção é necessária para o professor de educação básica, ao trabalhar com a língua, e para o professor das licenciaturas, ao compartilhar este entendimento com os futuros professores.

Para esclarecimentos, gostaríamos de justificar a escolha teórica e os encaminhamentos de nossa tese. As justificativas: é inegável que rever Saussure é inevitável no momento que pensamos no conceito de língua. Entretanto, mais do que isso, trabalhar com conceitos saussurianos apresentados no Curso de linguística geral (levando, mais uma vez, em consideração as particularidades da publicação) é trazer para as discussões empíricas, como àquelas acerca do ensino de língua, um dos linguistas mais estudados em cursos de Letras no Brasil e no mundo. Para nós, esse entendimento é importante para a formação dos professores. A escolha por Benveniste, por sua vez, também é extremamente justificável: ele é o mais saussuriano dos linguistas e é ele que ultrapassa Saussure ao levar em consideração um dos aspectos muito relevante para o trabalho com a língua na escola: o uso.

\section{A (enunciative) look at the concept of language in the classroom work}

\section{Abstract}

This article aims to discuss the concept of language in the Course on general linguistics, by Saussure (2012), and in the texts "The form and the meaning in language" and "Semiology of language", by Benveniste (1989). This theoretical choice is justified by the need to conceptualize language seeking a reflection on its teaching in the regular schools. From these readings, we realized that the relationship between the authors about the concept of language occurs, mainly, through the notion of sign, organized in a system. In this article, we also reflect on the relationship between 
the authors, which happens, above all, in the concern with the language in use, with the signs manifested in the community, which, undeniably, is relevant when we think of language teaching. To this end, we conducted a bibliographic and exploratory research, in which we realized that an enunciative notion of language is one of the possibilities of effective work with the mother tongue at school.

Keywords: Language concept. Native language teaching. Saussurian linguistics. Benvenistian linguistics.

\section{Notas}

1 Questões relacionadas à Semiologia enquanto ciência dos signos serão abordadas no decorrer deste artigo.

2 O fato de a língua respeitar a sua própria ordem nos lembra, inevitavelmente, Barthes (1997, p. 16): "Mas a língua não é nem reacionária nem progressista; ela é pura e simplesmente fascista; porque o fascismo não consiste em impedir de dizer, mas em obrigar a dizer". Ou seja, a língua nos obriga a dizer, em uma ordem específica, de uma determinada forma.

3 No texto "Semiologia da língua", Benveniste (1989) afirma que a escrita é um sistema de signos diferente da língua. Assim, entender a semiologia enquanto ciência dos sistemas de signos é importante para, posteriormente, compreendermos como a língua enquanto sistema se relaciona com a escrita enquanto sistema, percurso de pesquisa que realizaremos na tese, olhando, naquela situação, para o contexto do ensino da língua e da escrita na educação básica.

\section{Referências}

BARBISAN, Leci Borges; FLORES, Valdir do Nascimento. Sobre Saussure, Benveniste e outras histórias da linguística. In: NORMAND, Claudine. Convite à linguística. Tradução: Cristina de Campos Velho et al. São Paulo: Contexto, 2009. p. 7-22.
BARTHES, Roland. Lição. Tradução: Ana Mafalda Leite. Lisboa: Edições 70, 1997.

BENVENISTE, Émile. Problemas de linguística geral I. Campinas, SP: Pontes, 2005.

BENVENISTE, Émile. Problemas de linguística geral II. Campinas, SP: Pontes, 1989.

BRASIL. Lei no 9.394, de 20 de dezembro de 1996. Estabelece as diretrizes e bases da educação nacional. Diário Oficial da União: Seção 1, Brasília, DF, p. 27833, 23 dez. 1996.

FLORES, Valdir do Nascimento. Introdução à teoria enunciativa de Benveniste. São Paulo: Parábola, 2013.

FLORES, Valdir do Nascimento; TEIXEIRA, Marlene. Saussure, Benveniste e a teoria do valor: do valor e do homem na língua. Letras \& Letras, Uberlândia, v. 25, n. 1, p. 73-84, 10 dez. 2009.

FLORES, Valdir do Nascimento et al. $D i$ cionário de linguística da enunciação. São Paulo: Contexto, 2009.

NORMAND, Claudine. Convite à linguística . Tradução: Cristina de Campos Velho et al. São Paulo: Contexto, 2009.

SAUSSURE, Ferdinand de. Curso de linguística geral. Tradução: Antônio Chelini, José Paulo Paez e Izidoro Blikstein. São Paulo: Cultrix, 2012.

SALUM, Isaac Nicolau. Prefácio à edição brasileira. In: SAUSSURE, Ferdinand de. Curso de linguística geral. Tradução: Antônio Chelini, José Paulo Paez e Izidoro Blikstein. São Paulo: Cultrix, 2012. p. 11-20. 